\title{
Astragaloside IV blocks monocrotaline-induced pulmonary arterial hypertension by improving inflammation and pulmonary artery remodeling
}

\author{
HAIFENG JIN ${ }^{1,2}$, YU JIAO ${ }^{3}$, LINNA GUO ${ }^{1}$, YONG MA ${ }^{1}$, RONGJIE ZHAO ${ }^{3}$, XUEMEI LI ${ }^{4}$, \\ LEI SHEN ${ }^{1}$, ZHONGGUANG ZHOU ${ }^{5}$, SANG CHAN KIM ${ }^{6}$ and JICHENG LIU ${ }^{2}$
}

\begin{abstract}
${ }^{1}$ Department of Anatomy, ${ }^{2}$ Qigihar Institute of Medical and Pharmaceutical Sciences, ${ }^{3}$ Department of Psychopharmacology,
${ }^{4}$ Experiment and Practice Training Center, Qiqihar Medical University, Qiqihar, Heilongjiang 161006;

${ }^{5}$ Basic Discipline of Chinese and Western Integrative Medicine, Heilongjiang University of Chinese Medicine, Harbin, Heilongjiang 150000, P.R. China; ${ }^{6} \mathrm{MRC}-\mathrm{GHF}$, College of Korean Medicine,

Daegu Haany University, Gyeongsan, Gyeongsang 38610, Republic of Korea
\end{abstract}

Received June 24, 2020; Accepted November 18, 2020

DOI: $10.3892 / \mathrm{ijmm} .2020 .4813$

\begin{abstract}
Pulmonary arterial hypertension (PAH) is associated with increased inflammation and abnormal vascular remodeling. Astragaloside IV (ASIV), a purified small molecular saponin contained in the well-know herb, Astragalus membranaceus, is known to exert anti-inflammatory and anti-proliferation effects. Thus, the present study investigated the possible therapeutic effects of ASIV on monocrotaline (MCT)-induced PAH. Rats were administered a single intraperitoneal injection of MCT $(60 \mathrm{mg} / \mathrm{kg})$, followed by treatment with ASIV at doses of 10 and $30 \mathrm{mg} / \mathrm{kg}$ once daily for 21 days. Subsequently, right ventricle systolic pressure, right ventricular hypertrophy and serum inflammatory cytokines, as well as pathological changes of the pulmonary arteries, were examined. The effects of ASIV on the hypoxia-induced proliferation and apoptotic resistance of human pulmonary artery smooth muscle cells (HPASMCs) and the dysfunction of human pulmonary artery endothelial cells (HPAECs) were evaluated. MCT elevated pulmonary artery pressure and promoted pulmonary artery structural remodeling and right ventricular hypertrophy in the rats, which were all attenuated by both doses of ASIV used. Additionally, ASIV prevented the increase in the TNF- $\alpha$ and IL- $1 \beta$ concentrations in serum, as well as their gene expression in lung tissues induced by MCT. In in vitro experiments, ASIV attenuated the hypoxia-induced proliferation and apoptotic resistance of HPASMCs. In
\end{abstract}

Correspondence to: Professor Jicheng Liu, Qigihar Institute of Medical and Pharmaceutical Sciences, Qiqihar Medical University, 333 Bukui Street, Qiqihar, Heilongjiang 161006, P.R. China E-mail: jcliu@qmu.edu.cn

Key words: astragaloside IV, pulmonary arterial hypertension, inflammation, pulmonary artery endothelial cells, pulmonary artery smooth muscle cells addition, ASIV upregulated the protein expression of $\mathrm{p} 27$, p21, Bax, caspase-9 and caspase-3, whereas it downregulated HIF-1 $\alpha$, phospho-ERK and Bcl-2 protein expression in HPASMCs. Furthermore, in HPAECs, ASIV normalized the increased release of inflammatory cytokines and the increased protein levels of HIF-1 $\alpha$ and VEGF induced by hypoxia. On the whole, these results indicate that ASIV attenuates MCT-induced PAH by improving inflammation, pulmonary artery endothelial cell dysfunction, pulmonary artery smooth muscle cell proliferation and resistance to apoptosis.

\section{Introduction}

Pulmonary hypertension (PH) is a chronic and progressive disease with multiple etiologies and a high mortality rate. At the Sixth World Symposium on Pulmonary Hypertension, the hemodynamic definition of $\mathrm{PH}$ was proposed as a mean pulmonary artery pressure (mPAP) $>20 \mathrm{mmHg}$ (1). Based on the etiology and treatment modalities, the World Health Organization (WHO) has defined 5 groups of PH. Group 1 pulmonary arterial hypertension (PAH) encompasses diverse diseases that result in similar pathological changes within the pulmonary vasculature, which is a small subset of pulmonary hypertensive syndromes (WHO categories 2-5) $(2,3)$. PAH is characterized by the pathological vascular remodeling of arterial vessels and elevated pulmonary artery pressure, leading to pressure overload of the right ventricle (RV) and eventually, to heart failure.

Although the exact mechanisms responsible for the development of PAH remain unclear, several molecular and cellular abnormalities appear to play important roles. For example, pulmonary artery endothelial cell (PAEC) dysfunction, local inflammation, and the abnormal proliferation of pulmonary artery smooth muscle cells (PASMCs) underlie the pathological changes of PAH (4). PAECs are recognized as a major regulator of pulmonary vascular function, and their dysfunction leads to the imbalanced production of endogenous vasoconstrictors (serotonin and endothelin) and vasodilators 
(nitric oxide and prostacyclin) (5). In addition, in vitro analyses have demonstrated that the exposure of PAECs to hypoxia causes the synthesis and release of inflammatory cytokines, such as tumor necrosis factor- $\alpha$ (TNF- $\alpha)$ and interleukin (IL)-1 $\beta$ (6). These changes underpin the abnormal proliferation of PASMCs, and the abnormal vasoconstriction and remodeling of pulmonary vessels. Evidence from animal models and studies on patients with PAH suggests that inflammation may contribute to pulmonary vascular remodeling $(7,8)$. The number of inflammatory cells ( $\mathrm{T}$ and $\mathrm{B}$ lymphocytes, macrophages) and the level of cytokines (TNF- $\alpha$, IL-1 $\beta$, IL-6, IL-8) are increased in $\mathrm{PAH}$, and have been shown to participate in the initiation and progression of PAH by directly modulating the proliferation and migration of pulmonary vascular cells $(9,10)$. In addition, the emergence of highly proliferative and apoptosis-resistant PASMCs acts as a hallmark of pulmonary vessel wall thickening and vascular remodeling (11), and there is evidence to indicate that the improvement of vascular remodeling by normalizing the abnormal proliferation of PASMCs is an effective strategy for the treatment of PAH $(12,13)$. Taken together, attenuating PAEC dysfunction, inhibiting inflammation and reducing the abnormal proliferation of PASMCs are promising approaches for the prevention and treatment of PAH.

Among the several existing experimental models of $\mathrm{PAH}$, the monocrotaline (MCT) model is perhaps the one that has most contributed to the understanding of PAH pathophysiology (14). MCT is derived from the plant, Crotalaria spectabilis. A single dose of MCT (usually $60 \mathrm{mg} / \mathrm{kg}$, intraperitoneally or subcutaneously) reliably causes PAH in rats within 3 to 4 weeks (15). The MCT model has the advantage of mimicking several key aspects of human PAH, such as pulmonary vascular remodeling, RV failure, PASMC proliferation, PAEC dysfunction and the increased expression of inflammatory cytokines (14).

Astragalus membranaceus, the main ingredient of the majority of Chinese herbal antidiabetic formulas, exerts protective effects on the cardiovascular system, the immune system and the nervous system $(16,17)$. Astragalus membranaceus contains saponins, polysaccharides and flavonoids. Astragaloside IV (ASIV, 3- $O$ - $\beta$-D-xylopyranosyl-6- $O$ - $\beta$-Dglucopyranosylcyl-cloastragenol) is a purified small molecular saponin included in Astragalus membranaceus that has a wide range of pharmacological properties, such as antioxidant, anti-inflammatory, antidiabetic, antitumor, immunoregulatory and antiviral activities (18-20). ASIV has been shown to exert protective effects against cardiovascular disease and pulmonary fibrosis (21-23). These findings suggest that ASIV may exert a therapeutic effect against PAH.

Several classes of drugs are currently used clinically in the treatment of PAH; however, their usage is greatly compromised by either limited effectiveness or unwanted side-effects. This reality highlights the urgent need for the development of novel pharmaceutical candidates for PAH. Screening and identifying bioactive compounds from herbs that exert therapeutic effects on the cardiovascular system is a promising approach. Therefore, in the present study, the possible protective effects of ASIV on PAH were evaluated, and the relevant mechanisms were investigated.

\section{Materials and methods}

Reagents and antibodies. ASIV was purchased from Shanghai Yuanye Bio-Technology Co., Ltd. (HPLC >98\%; cat. no. C14J9Q65734). High-glucose Dulbecco's modified Eagle's medium (DMEM) and fetal bovine serum (FBS) were purchased from HyClone Laboratories, Inc. Endothelial cell medium (ECM) and endothelial cell growth supplement (ECGS) were purchased from ScienCell Research Laboratories. MCT, dimethyl sulfoxide (DMSO), tribromoethanol, and hematoxylin and eosin were purchased from Sigma-Aldrich; Merck KGaA. Rabbit monoclonal anti-hypoxia-inducible factor (HIF)-1 $\alpha$ (\#14179), rabbit monoclonal anti-phospho-ERK1/2 (p-ERK1/2; \#4377), rabbit polyclonal anti-total ERK1/2 (\#9102), mouse monoclonal anti-p27 (\#3698), rabbit monoclonal anti-p21 (\#2947), and mouse monoclonal anti-Bcl-2 (\#15071) were purchased from Cell Signaling Technology, Inc. Mouse monoclonal anti-Bax 6A7 (sc-23959), mouse monoclonal anti-vascular endothelial growth factor (VEGF; sc-7269), mouse monoclonal anti- $\alpha$-smooth muscle actin (SMA; sc-53142) and mouse monoclonal anti-proliferating cell nuclear antigen (PCNA; sc-56) were purchased from Santa Cruz Biotechnology, Inc. Rabbit monoclonal anti-cleaved caspase-3 (AC033), mouse monoclonal anti-cleaved caspase-9 (AC062), mouse monoclonal anti-GAPDH (AF0006), horseradish peroxidase-conjugated goat anti-rabbit IgG (A0208), goat anti-mouse IgG (A0216) and 3-(4,5-dimethylthiazol-2-yl)-2,5 diphenyl-tetrazolium bromide (MTT; ST316) were purchased from Beyotime Institute of Biotechnology.

Animal experiments. Male Sprague-Dawley rats, 8 weeks old weighing 200-230 g, were obtained from the Animal Center of Qiqihar Medical University. The protocol for the present study was approved by the Qiqihar Medical University Institutional Review Board (no. QMU-AECC-2018-27). The rats were housed in a temperature- and humidity-controlled environment with 12-h light/dark cycles. Food and water were available ad libitum. The experiments conformed to the National Institutes of Health guidelines concerning the care and use of laboratory animals, and all animal procedures were approved by the Animal Care and Use Committee of the Qiqihar Medical University. The rats were randomly assigned to 4 groups (8 rats per group) as follows: The control group, the MCT group, the MCT $+10 \mathrm{mg} / \mathrm{kg} /$ dahy ASIV (ASIV10) group, and the MCT $+30 \mathrm{mg} / \mathrm{kg} /$ day ASIV (ASIV30) group. To establish MCT-induced PAH, the rats were administered a single intraperitoneal injection of MCT $(60 \mathrm{mg} / \mathrm{kg})$, while the control group received the same volume of saline. MCT was dissolved in $1 \mathrm{~N} \mathrm{HCl}$, diluted in sterile saline and adjusted to $\mathrm{pH} 7.4$ with $1 \mathrm{~N} \mathrm{NaOH}$. ASIV was initially dissolved in DMSO as a stock solution and further diluted in saline immediately prior to use; the final DMSO concentration was $0.5 \%$. Within hours of the MCT injection, there were signs of pulmonary vascular endothelial damage, but without an increase in pulmonary artery pressure. By 2 weeks, pulmonary artery pressure began to increase, as previously described (24). At 2 days following the MCT administration, ASIV or the vehicle (0.5\% DMSO in saline) were administered intraperitoneally once a day for 21 days. 
Hemodynamic experiments. Rats were anesthetized by an intraperitoneal injection of tribromoethanol $(250 \mathrm{mg} / \mathrm{kg})$, and a polyethylene (PE) catheter was inserted into the RV through the right jugular vein. Then, the RV systolic pressure (RVSP) was measured using a force transducer and recorded via PowerLab Software (ADInstruments). After hemodynamic measurements, the right carotid artery was inserted with a polyethylene catheter to collect blood samples for further biochemical assay. The rats were then euthanized by $\mathrm{CO}_{2}$ exposure $\left(\mathrm{CO}_{2}\right.$ displacement rate equivalent to $20 \%$ of the chamber volume/min; these experiments were performed in 2019) and cervical dislocation, and the lung and heart tissues were collected for following analyses. To assess the hypertrophy degree of the RV, the hearts were divided into the $\mathrm{RV}$ and left ventricle plus septum $(\mathrm{LV}+\mathrm{S})$. The weight ratio of $\mathrm{RV} /(\mathrm{LV}+\mathrm{S})$, known as the Fulton index, was calculated to indicate RV hypertrophy.

Morphological investigation. The lungs were dissected into 3-mm-thick slices and soaked in 4\% neutral-buffered formalin. The lung slices were subjected to paraffin embedding and sectioned into $4-\mu \mathrm{m}$-thick sections. The lung sections were then dewaxed in xylene, hydrated with graded ethanol and stained with hematoxylin and eosin. To assess pulmonary artery structural remodeling, the percentage medial wall thickness $(\mathrm{WT} \%)=$ (outside diameter-inside diameter)/(outside diameter) x100 and the percentage medial wall area $(\mathrm{WA} \%)=($ medial wall area $) /($ total vessel area $) \times 100$ were calculated, as previously described (25).

Immunohistochemical staining. Lung sections were dewaxed in xylene and hydrated with graded ethanol, and antigens were retrieved. Unspecific protein binding was blocked with $5 \%$ bovine serum albumin for $30 \mathrm{~min}$ at room temperature. After rinsing with phosphate-buffered saline, the lung sections were incubated overnight with anti- $\alpha$-SMA antibody (1:500) or anti-PCNA antibody $(1: 1,000)$ at $4{ }^{\circ} \mathrm{C}$. The sections were then incubated with a biotinylated anti-mouse IgG antibody diluted at 1:500 for $1 \mathrm{~h}$ at room temperature. Immunoreactivity was visualized using diaminobenzidine. The sections were then counterstained with hematoxylin for $5 \mathrm{~min}$ at room temperature. Quantitative immunohistochemical assessments of $\alpha$-SMA and PCNA were performed as previously described (25).

Reverse transcription-quantitative polymerase chain reaction $(R T-q P C R)$. Total RNA was extracted from each sample using TRIzol reagent (Invitrogen; Thermo Fisher Scientific, Inc.) and subjected to reverse transcription using the PrimeScript ${ }^{\mathrm{TM}}$ RT reagent kit (Takara Bio, Inc.). RT-qPCR analysis was performed using the Applied LightCycler 2.0 detection system (Roche Applied Science) and the SYBR-Green I reagent (Takara Bio, Inc.) following the manufacturers' instructions. The relative expression levels of TNF- $\alpha$ and IL- $1 \beta$ were calculated using $\beta$-actin as an internal control by the $2^{-\Delta \Delta C q}$ method (26). The sequences of the primers were as follows: TNF- $\alpha$ forward, 5'-ATGAGC ACAGAAAGCATGATC-3' and reverse, 5'-TACAGGCTT GTCACTCGAATT-3'; IL-1 $\beta$ forward, 5'-TACCTATGTCTT GCCCGTGGAG-3' and reverse, 5'-ATCATCCCACGAGTC
ACAGAGG-3'; and $\beta$-actin forward, 5'-CTGTGCCCATCT ATGAGGGT-3' and reverse, 5'-CAGTGAGGCCAGGAT AGAGC-3'.

Cell culture and hypoxia in vitro. Primary human PAECs (HPAECs) and human PASMCs (HPASMCs) were obtained from ScienCell Research Laboratories. The HPAECs were cultured in ECM (5\% FBS, 1\% ECGS), the HPASMCs were cultured in DMEM supplemented with $10 \%$ FBS, and the cells used in the experiments were between passages 3 and 8 . The cells were divided into 6 groups as follows: The normoxia, hypoxia, hypoxia $+10 \mu \mathrm{M}$ ASIV, hypoxia $+20 \mu \mathrm{M}$ ASIV, hypoxia $+40 \mu \mathrm{M}$ ASIV, and hypoxia $+80 \mu \mathrm{M}$ ASIV groups, and then cultured either under normoxic $\left(21 \% \mathrm{O}_{2}\right.$ and $\left.5 \% \mathrm{CO}_{2}\right)$ or hypoxic $\left(2 \% \mathrm{O}_{2}\right.$ and $\left.5 \% \mathrm{CO}_{2}\right)$ conditions for $24 \mathrm{~h}$.

HPASMC proliferation analysis. The proliferation of HPASMCs was assessed by MTT assay. The HPASMCs in each group were placed in 96-well plates $(5,000$ cells per well) and then cultured under either normoxic or hypoxic conditions. Following treatment, an MTT solution was added to each well at a $5 \mathrm{mg} / \mathrm{ml}$ concentration, and the plates were incubated at $37^{\circ} \mathrm{C}$ for $4 \mathrm{~h}$. DMSO was then added. The optical density (OD) of the samples was measured at $570 \mathrm{~nm}$ in a microplate spectrophotometer (BioTek Instruments, Inc.).

Detection of apoptosis. Lung tissue sections or HPASMC apoptosis was evaluated by TUNEL staining using the terminal deoxyribonucleotidyl transferase-mediated dUTP nick end-labeling (TUNEL) Apoptosis Assay kit (Beyotime Institute of Biotechnology) according to the manufacturer's instructions. In brief, lung tissue sections were dewaxed in xylene and dehydrated with graded ethanol, and incubated with $3 \% \mathrm{H}_{2} \mathrm{O}_{2}$ at room temperature for $10 \mathrm{~min}$. The sections were then incubated with proteinase $\mathrm{K}$ at room temperature for $30 \mathrm{~min}$. The sections were then incubated with the TUNEL reaction mixture for $1 \mathrm{~h}$ at $37^{\circ} \mathrm{C}$ in the dark. Apoptotic cells were visualized with diaminobenzidine, which exhibited a brown color. The sections were then counterstained with hematoxylin for $5 \mathrm{~min}$ at room temperature. In each tissue section, 3 pulmonary arteries at $\mathrm{x} 200$ magnification were randomly selected, and the percentage of positive cells was quantified using Image Pro Plus software (Media Cybernetics, Inc.). For in vitro analysis, HPASMCs were fixed in $4 \%$ paraformaldehyde for $30 \mathrm{~min}$ at room temperature. Subsequently, the cells were treated with $0.3 \%$ Triton X-100 for $5 \mathrm{~min}$ at room temperature, and then incubated with the TUNEL reaction mixture for $1 \mathrm{~h}$ at $37^{\circ} \mathrm{C}$ in the dark. Localized green fluorescence of apoptotic FITC-labeled TUNEL-positive cells was imaged using a fluorescence microscope (Carl Zeiss), and images of 4 random and non-overlapping fields were selected from each well of 12 -well plates at x400 magnification for analysis.

Assay of TNF- $\alpha$ and $I L-1 \beta$. Blood samples from each rat were centrifuged at $1,500 \mathrm{x} \mathrm{g}$ for $20 \mathrm{~min}$ at $4^{\circ} \mathrm{C}$, and serum was separated. The sera and supernatants of HPAEC culture media were collected. TNF- $\alpha$ and IL-1 $\beta$ concentrations in the serum 

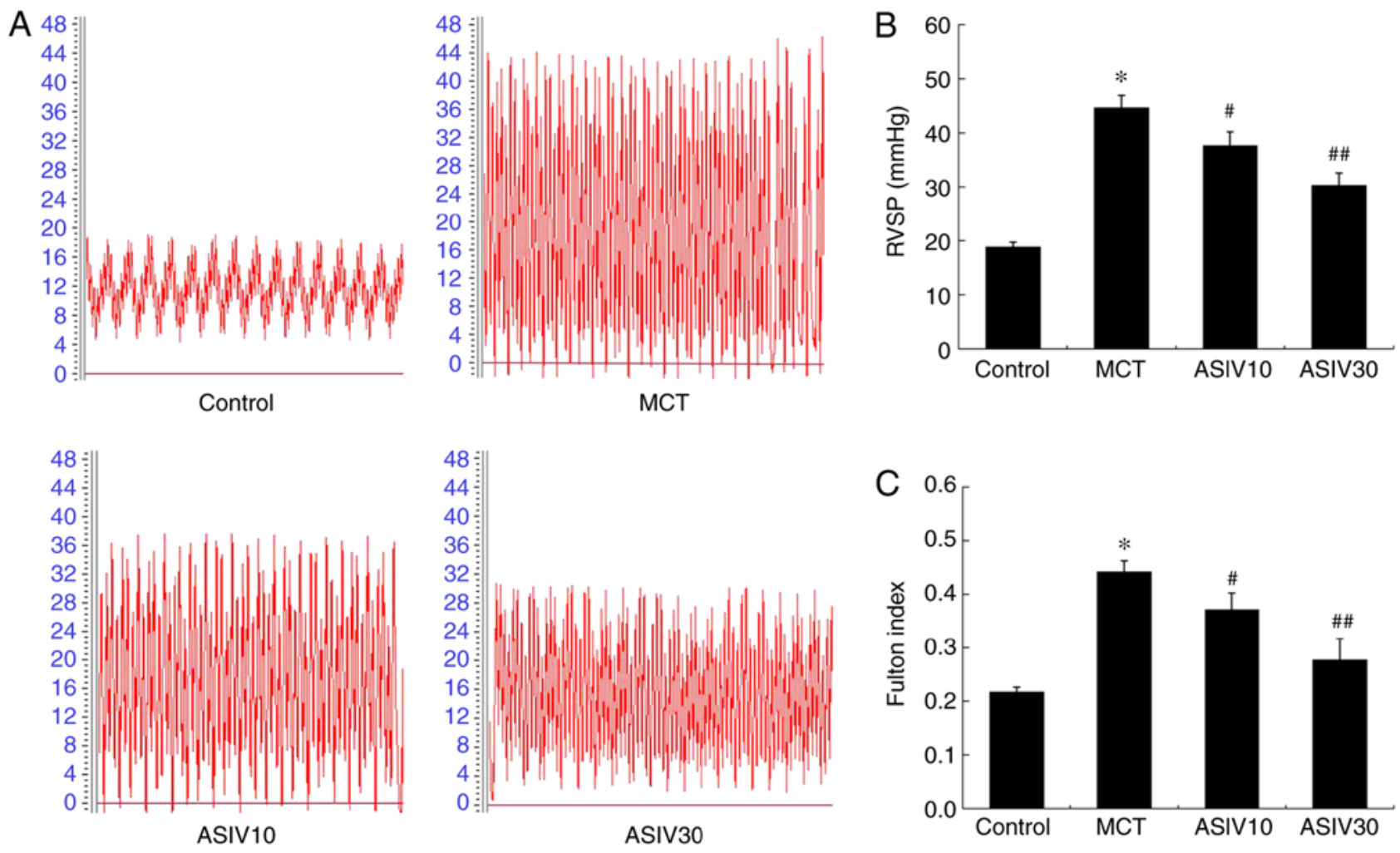

Figure 1. ASIV attenuates pulmonary arterial pressure and RV hypertrophy. (A) Representative RVSP waves in rats. (B) RVSP in rats. (C) Fulton index in rats. Values are the means \pm SEM ( $\mathrm{n}=8$ rats/group). ${ }^{*} \mathrm{P}<0.01$ compared with the control group; ${ }^{*} \mathrm{P}<0.05 ;{ }^{* \#} \mathrm{P}<0.01$, compared with the MCT group. ASIV, astragaloside IV; MCT, monocrotaline; ASIV10, MCT $+10 \mathrm{mg} / \mathrm{kg} / \mathrm{day}$ ASIV group; ASIV30, MCT $+30 \mathrm{mg} / \mathrm{kg} / \mathrm{day}$ group; RV, right ventricle; RVSP, right ventricular systolic pressure.

or supernatants were measured using enzyme-linked immunosorbent assay (ELISA) kits (Shanghai Jianglai Industrial Co., Ltd.) according to the manufacturer's instructions.

Western blot analysis. Cellular proteins were extracted using RIPA lysis buffer containing protease and phosphatase inhibitors (Beyotime Institute of Biotechnology). The protein concentrations were determined with a BCA protein assay kit (Beyotime Institute of Biotechnology). Equal amounts of protein $(30 \mu \mathrm{g})$ were separated on $10 \%$ sodium dodecyl sulfate polyacrylamide gels and transferred to polyvinylidene fluoride membranes. After blocking with 5\% (W/V) non-fat milk at room temperature for $2 \mathrm{~h}$, the membranes were incubated with primary antibodies against HIF-1 $\alpha(1: 1,000)$, p-ERK $1 / 2$ $(1: 1,000)$, total ERK1/2 $(1: 2,000)$, cleaved caspase-3 $(1: 1,000)$, cleaved caspase-9 (1:1,000), p27 (1:1,000), p21 (1:1,000), Bcl-2 $(1: 1,000), \operatorname{Bax}(1: 1,000), \operatorname{VEGF}(1: 1,000)$ and GAPDH $(1: 2,000)$ at $4{ }^{\circ} \mathrm{C}$ overnight. The membranes were then incubated with corresponding horseradish peroxidase-conjugated secondary antibodies at room temperature for $1 \mathrm{~h}$. Immunoreactive proteins were detected by enhanced chemiluminescence (ECL) solution (Beyotime Institute of Biotechnology), and densitometric analysis was performed with the use of a Gel Imaging System 4.2 (Tanon, Tanon Science \& Technology Co., Ltd.).

Statistical analyses. All data are presented as the means \pm SEM. Statistical analysis was performed using SPSS 11.5 (SPSS, Inc.). Statistical comparisons were performed by one-way analysis of variance (ANOVA) followed by the Holm-Sidak post hoc test. A significant difference was accepted at $\mathrm{P}<0.05$.

\section{Results}

ASIV attenuates pulmonary arterial pressure and pulmonary artery structural remodeling. The rats in the MCT group exhibited a higher RVSP than those of the control group, indicating the establishment of PAH. However, treatment with both doses of ASIV (10 and $30 \mathrm{mg} / \mathrm{kg} /$ day) prevented this pathophysiological change (Fig. 1A and B). The Fulton index in the MCT group was markedly elevated compared with that in the control group, which was also normalized by treatment with ASIV (Fig. 1C). Furthermore, as shown in Fig. 2, the MCT significantly elevated WA and WT\%, while treatment with 10 and $30 \mathrm{mg} / \mathrm{kg} / \mathrm{day}$ ASIV attenuated these pathological changes, marking the improvement of pulmonary artery structural remodeling.

ASIV attenuates the increased expression of $\alpha$-SMA. In the present study, the levels of $\alpha$-SMA reflected the hyperplastic smooth muscularization of pulmonary arteries (Fig. 3). The integrated OD value of $\alpha$-SMA in the MCT group was elevated compared with that in the control group. However, both doses of ASIV inhibited the elevation of the OD value of $\alpha$-SMA.

ASIV attenuates PASMC proliferation. To evaluate the role of ASIV in PASMC proliferation, PCNA expression was measured in the medial wall of pulmonary arteries. As shown in Fig. 4, 


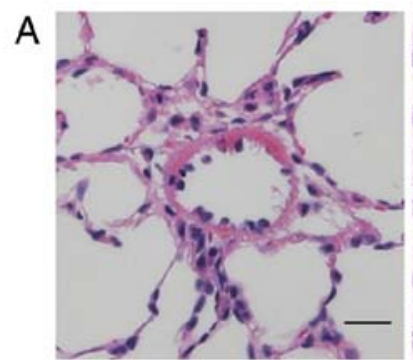

Control

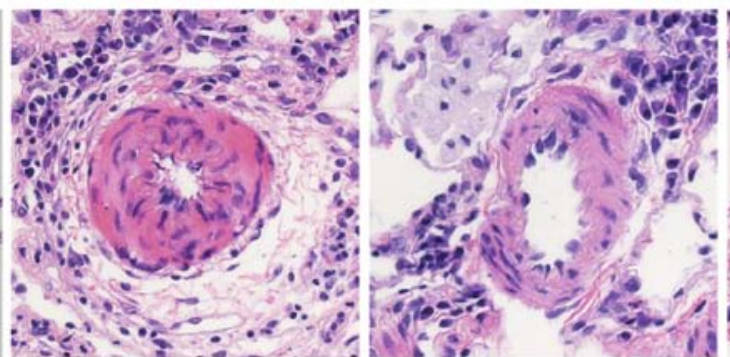

ASIV10



ASIV30
B



C

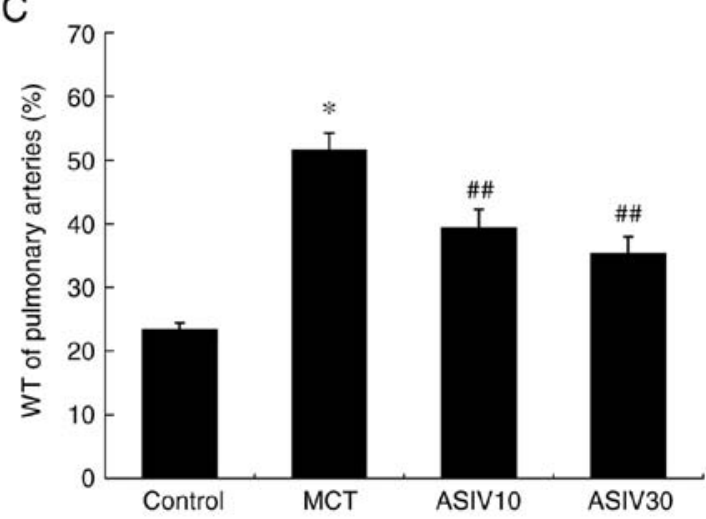

Figure 2. ASIV attenuates pulmonary artery structural remodeling. (A) Hematoxylin and eosin staining of pulmonary arteries (scale bar, $50 \mu \mathrm{m}$ ). (B) Medial wall area (WA\%) of pulmonary arteries. (C) Medial wall thickness (WT\%) of pulmonary arteries. Values are the means \pm SEM (n=8 rats/group). "P $<0.01$ compared with the control group; ${ }^{\# \prime} \mathrm{P}<0.01$, compared with the MCT group. ASIV, astragaloside IV; MCT, monocrotaline; ASIV10, MCT + 10 mg $/ \mathrm{kg} / \mathrm{day}$ ASIV group; ASIV30, MCT $+30 \mathrm{mg} / \mathrm{kg} /$ day group.
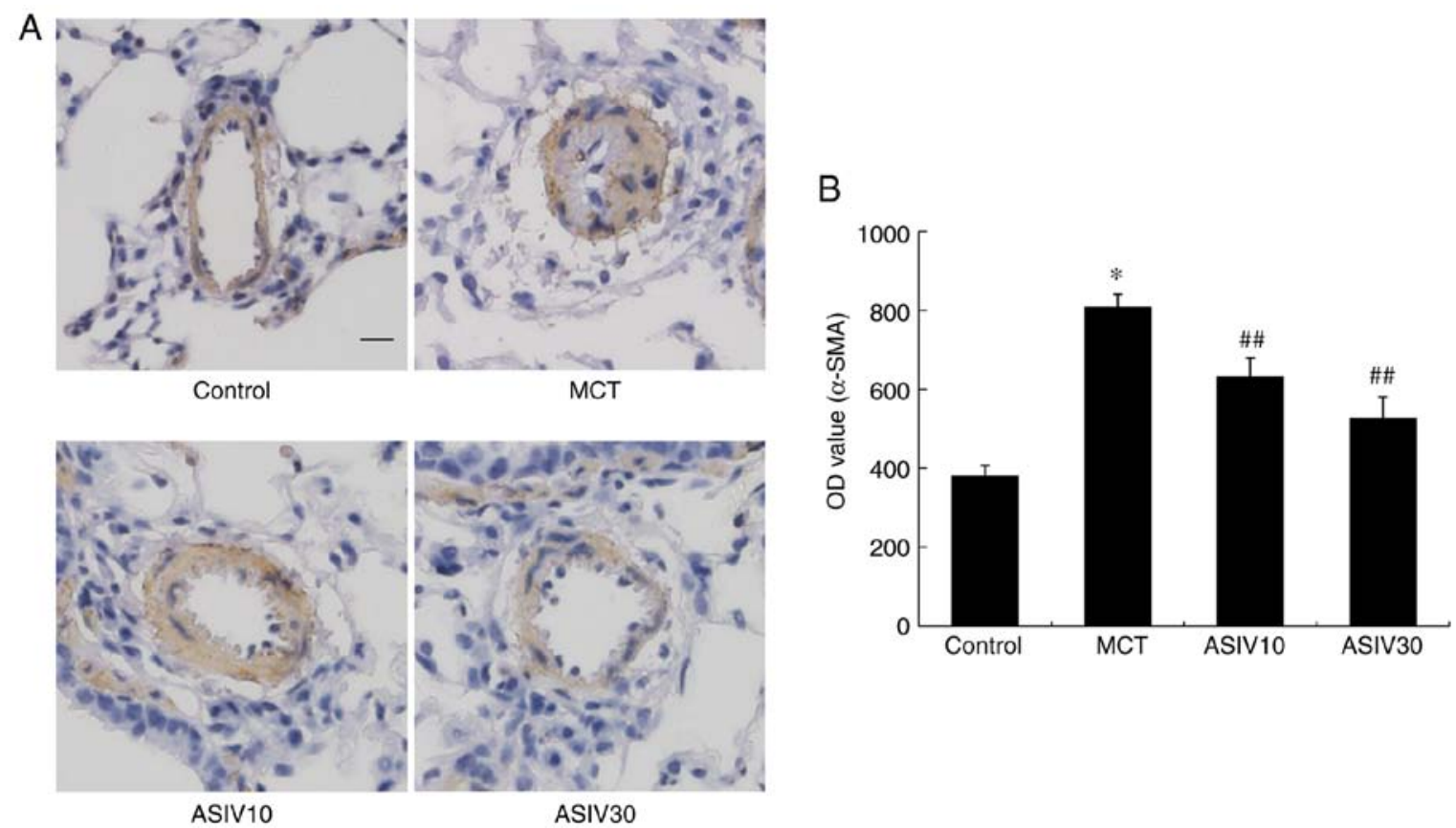

Figure 3. ASIV attenuates $\alpha$-SMA expression in pulmonary arteries. (A) Immunohistochemical staining of $\alpha$-SMA of pulmonary arteries (scale bar, $50 \mu \mathrm{m}$ ). (B) Quantitative analysis of the OD value of $\alpha$-SMA immunoreactivity in pulmonary arteries. Values are the means \pm SEM (n=6 rats/group randomly selected for this experiment). " $\mathrm{P}<0.01$ compared with the control group; ${ }^{\# \#} \mathrm{P}<0.01$, compared with the MCT group. ASIV, astragaloside IV; MCT, monocrotaline; ASIV10, MCT $+10 \mathrm{mg} / \mathrm{kg} /$ day ASIV group; ASIV30, MCT $+30 \mathrm{mg} / \mathrm{kg} /$ day group.

the numbers of PCNA-positive cells in the rats of the MCT group were significantly increased compared with those of the control animals. However, treatment with both doses of ASIV reduced the abnormal PASMC proliferation. Additionally, in the in vitro experiments, the results of MTT assay revealed that ASIV inhibited the hypoxia-induced HPASMC proliferation, and the effects were concentration-dependent (Fig. 5). Moreover, the results of western blot analysis found that ASIV 

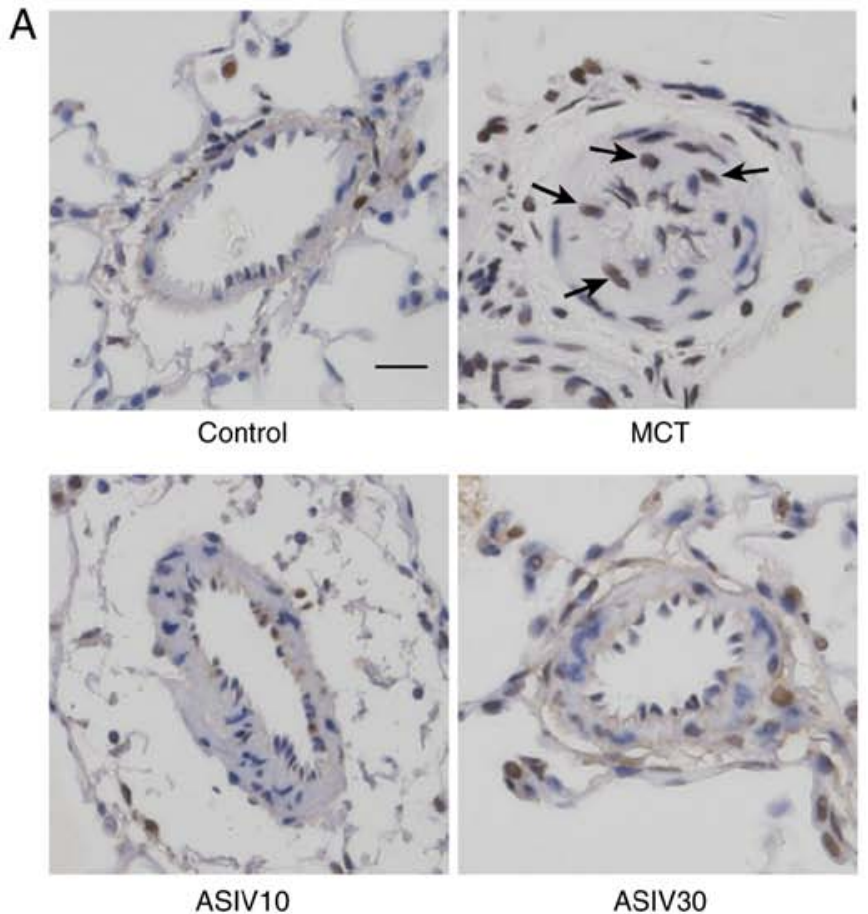

B

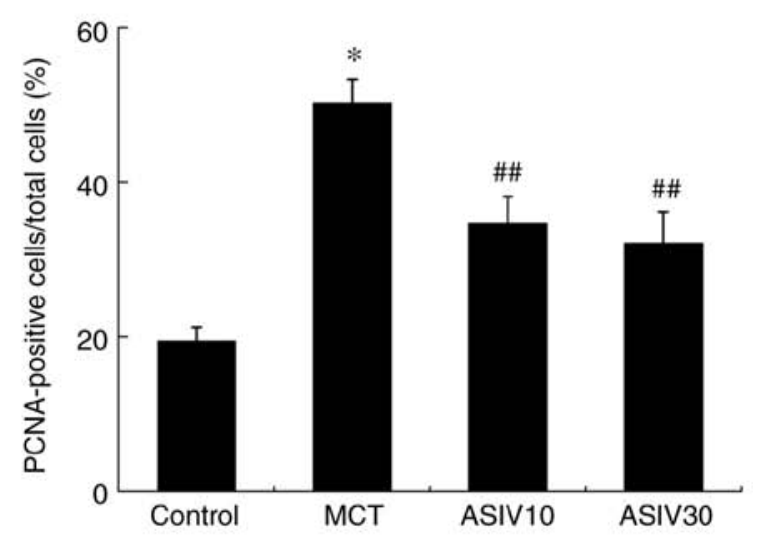

Figure 4. ASIV decreases PCNA expression in the medial wall of pulmonary arteries. (A) Immunohistochemical staining of PCNA of pulmonary arteries (scale bar, $50 \mu \mathrm{m}$ ). (B) The number of PCNA-positive cells relative to the total smooth muscle cells in the medial wall of pulmonary arteries (\%). Values are means \pm SEM ( $\mathrm{n}=6$ rats/group randomly selected for this experiment). ${ }^{*} \mathrm{P}<0.01$ compared with the control group; ${ }^{* \#} \mathrm{P}<0.01$, compared with the MCT group. ASIV, astragaloside IV; MCT, monocrotaline; ASIV10, MCT + $10 \mathrm{mg} / \mathrm{kg} /$ day ASIV group; ASIV30, MCT + $30 \mathrm{mg} / \mathrm{kg} /$ day group.

also reversed the enhancement of HIF-1 $\alpha$ and p-ERK1/2 protein expression, and the decreases in p27 and p21 levels in the HPASMCs induced by hypoxia (Fig. 6).

ASIV contributes to PASMC apoptosis. To determine the effects of ASIV on the apoptotic resistance of PASMCs, a TUNEL assay was performed. As shown in Fig. 7, disrupted apoptosis was observed in the MCT group, while both concentrations of ASIV significantly increased PASMC apoptosis. In the in vitro experiments, apoptotic HPASMCs were illustrated by the green fluorescence of the free labeled 3'-OH termini (Fig. 8A and B). The results revealed that the percentage of apoptotic cells under hypoxic conditions was markedly decreased compared with that under normoxic conditions, while hypoxia-induced apoptotic resistance was reversed by ASIV. In addition, the levels of apoptosis-related proteins in the HPASMCs were detected by western blot analysis (Fig. 8C-F). Hypoxia markedly decreased the levels of the pro-apoptotic proteins, Bax, cleaved caspase-9 and cleaved caspase-3, while it increased the expression of the anti-apoptotic protein, Bcl-2, in HPASMCs. However, ASIV treatment normalized these alterations.

ASIV prevents the elevation of TNF- $\alpha$ and IL-1 $\beta$ levels. To determine the anti-inflammatory effects of ASIV, TNF- $\alpha$ and IL-1 $\beta$ levels were analyzed in serum (Fig. 9A and B). The serum levels of TNF- $\alpha$ and IL- $1 \beta$ were elevated in the MCT group, while both doses of ASIV suppressed these elevations. Similarly, RT-qPCR analysis revealed that the mRNA expression of TNF- $\alpha$ and IL- $1 \beta$ in lung tissues was upregulated in the MCT group compared with the control group, which was also normalized by both doses of ASIV (Fig. 9C and D).

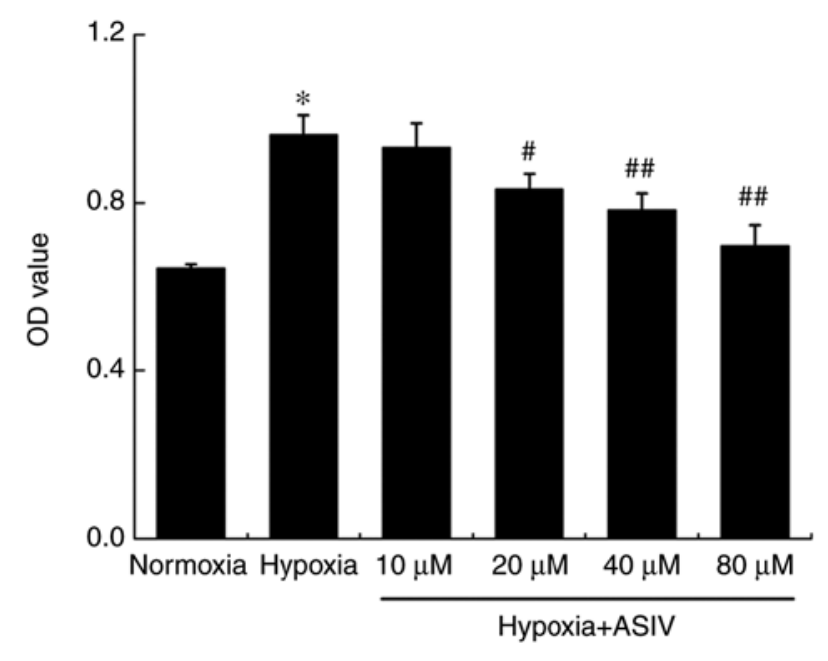

Figure 5. ASIV inhibits hypoxia-induced HPASMC proliferation. HPASMC proliferation was measured following treatment with various concentrations of ASIV under normoxic or hypoxic conditions. Values are the means \pm SEM of 4 independent experiments. " $\mathrm{P}<0.01$ compared with the normoxia group; ${ }^{\#} \mathrm{P}<0.05 ;{ }^{\# \prime} \mathrm{P}<0.01$, compared with the hypoxia group. ASIV, astragaloside IV; HPASMC, human pulmonary artery smooth muscle cell.

ASIV improves HPAEC dysfunction. Hypoxia increased the concentrations of TNF- $\alpha$ and IL- $1 \beta$ in the supernatants of the HPAEC culture media compared with normoxia. However, ASIV treatment prevented these changes in a concentration-dependent manner (Fig. 10A and B). In addition, western blot analysis revealed that hypoxia also increased the HIF-1 $\alpha$ and VEGF protein levels in HPAECs, which were reversed by ASIV treatment (Fig. 10C and D). 

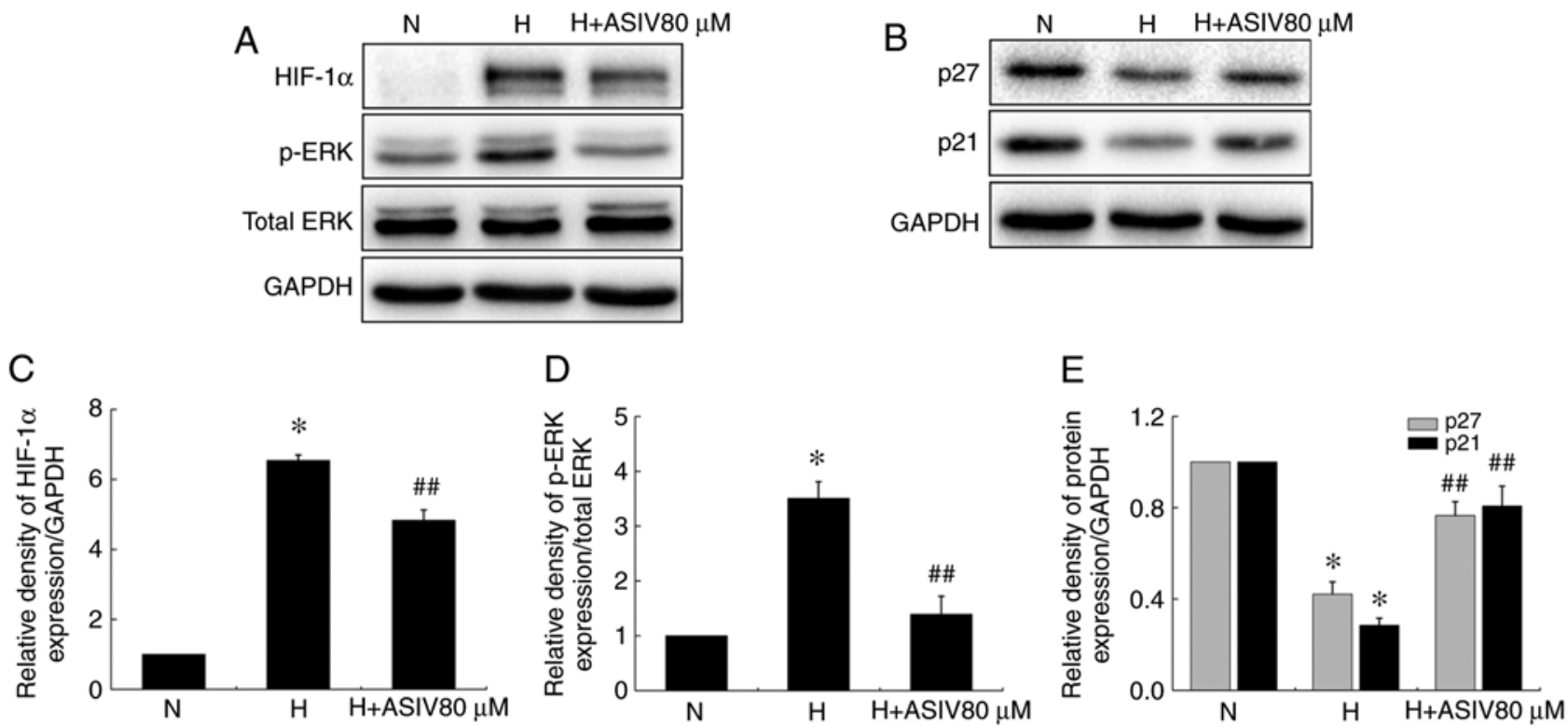

Figure 6. ASIV decreases HIF-1 $\alpha$ and p-ERK1/2 protein levels, and increases p27 and p21 protein levels in HPASMCs. (A and B) Western blot analysis of HIF-1 $\alpha$, p-ERK1/2, p27 and p21 protein levels in HPASMCs under normoxic or hypoxic conditions. (C-E) HIF-1 $\alpha$, p-ERK1/2, p27 and p21 protein levels, respectively (relative to normoxia group). Values are means \pm SEM of 3 independent experiments. ${ }^{*} \mathrm{P}<0.01$ compared with the normoxia group; ${ }^{\# \#} \mathrm{P}<0.01$, compared with the hypoxia group. ASIV, astragaloside IV; HPASMCs, human pulmonary artery smooth muscle cells; N, normoxia; H, hypoxia.

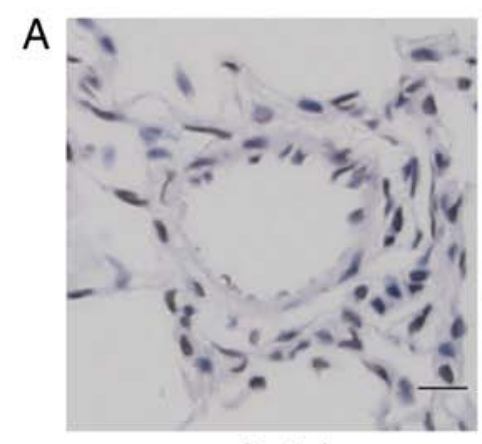

Control



ASIV10

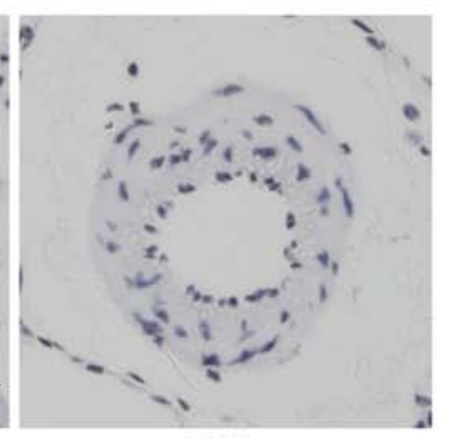

MCT

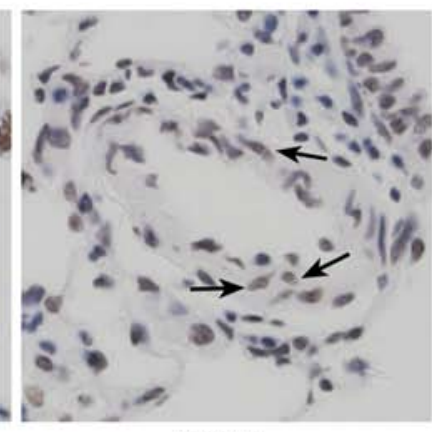

B



Figure 7. ASIV promotes PASMC apoptosis. (A) TUNEL assay in the pulmonary arteries (scale bar, $50 \mu \mathrm{m}$ ). (B) Number of TUNEL-positive cells relative to the total smooth muscle cells in the medial wall of pulmonary arteries (\%). Values are the means \pm SEM ( $\mathrm{n}=6$ rats/group randomly selected for this experiment). ${ }^{* *} \mathrm{P}<0.05$ compared with the control group; ${ }^{\# \#} \mathrm{P}<0.01$, compared with the MCT group. ASIV, astragaloside IV; PASMC, pulmonary artery smooth muscle cell; MCT, monocrotaline; ASIV10, MCT + $10 \mathrm{mg} / \mathrm{kg} /$ day ASIV group; ASIV30, MCT + $30 \mathrm{mg} / \mathrm{kg} /$ day group.

\section{Discussion}

In the present study, the rats in the MCT group exhibited significant pulmonary artery remodeling, an increased pulmonary artery pressure and right ventricular hypertrophy. However, these pathophysiological changes were improved by both doses of ASIV. Additionally, ASIV suppressed the elevation of TNF- $\alpha$ and IL- $1 \beta$ secretion in serum and their gene expression in lung tissues induced by MCT. Furthermore, in the in vivo and in vitro experiments, ASIV normalized the abnormal proliferation and apoptosis resistance of PASMCs and PAEC dysfunction. These results indicate that ASIV exerts 




Normoxia

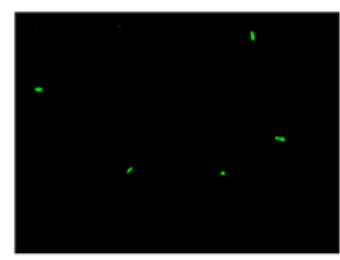

ASIV10

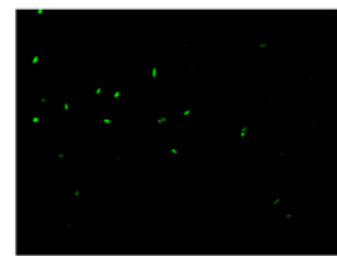

ASIV40

C

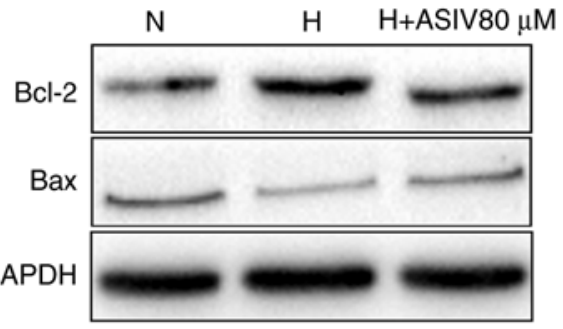

E

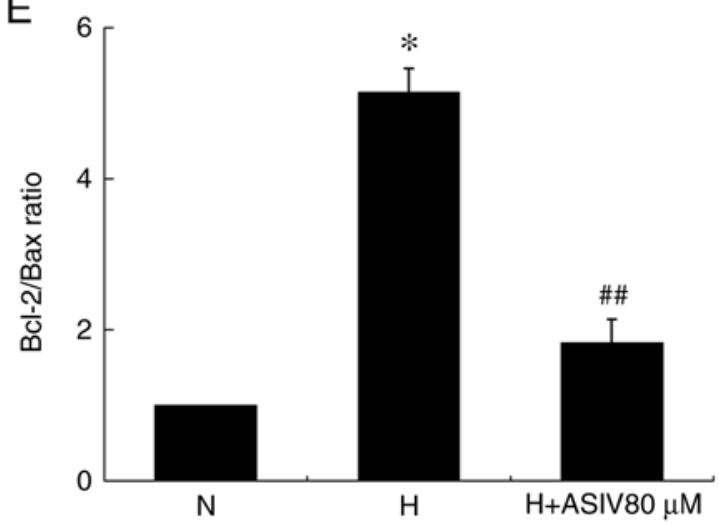

B

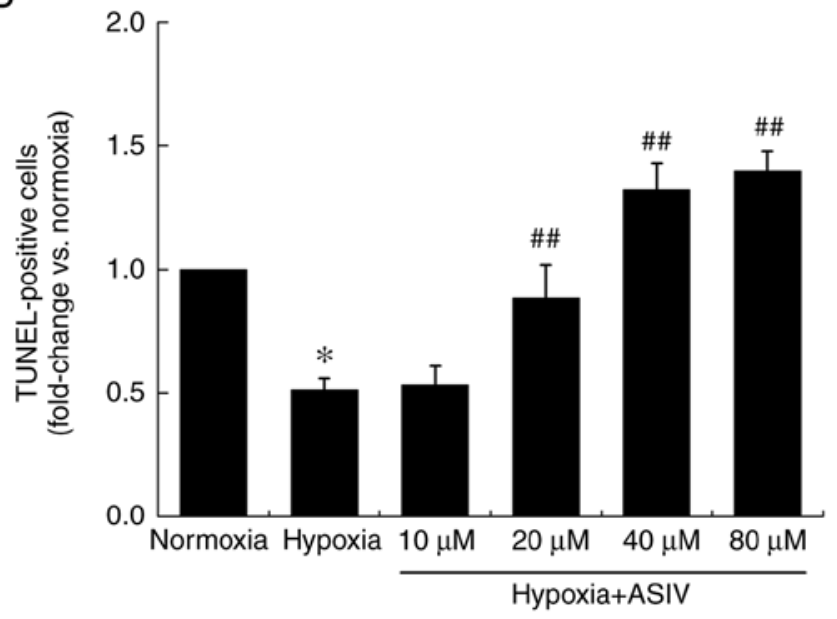

D

Cleaved caspase-3

Cleaved caspase-9

GAPDH

$\begin{array}{lll}\mathrm{N} & \mathrm{H} & \mathrm{H}+\mathrm{ASIV} 80 \mu \mathrm{M}\end{array}$



F

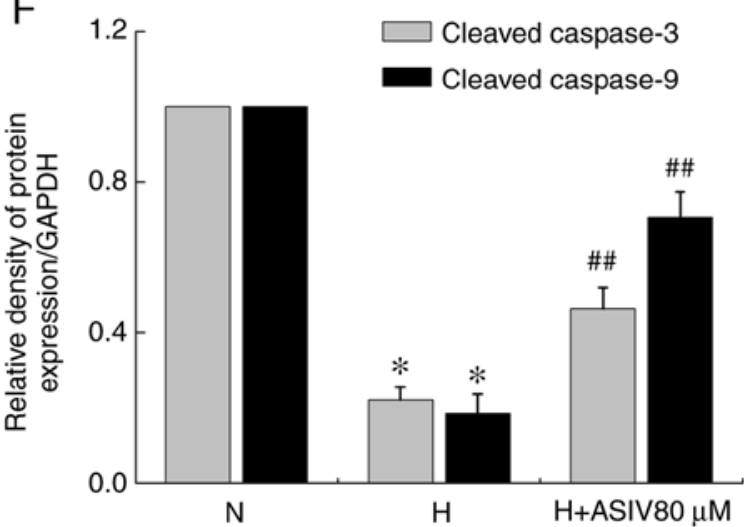

Figure 8. ASIV promotes HPASMC apoptosis. (A) Representative images of TUNEL-positive HPASMCs treated with various concentrations of ASIV under normoxic or hypoxic conditions. Cells undergoing apoptosis were positively stained with TUNEL reagent and are shown in green (scale bar, $100 \mu \mathrm{m}$ ). (B) TUNEL-positive HPASMC expression (relative to normoxia group). (C and D) Western blot analysis of Bcl-2, Bax, cleaved caspase-3 and cleaved caspase-9 protein levels in HPASMCs under normoxic or hypoxic conditions. (E) Ratio of Bcl-2/Bax (relative to normoxic group). (F) Cleaved caspase-3 and cleaved caspase-9 protein levels, respectively (relative to normoxic group). Values are the means \pm SEM of 3 independent experiments. "P<0.01 compared with the normoxia group; ${ }^{\# \#} \mathrm{P}<0.01$, compared with the hypoxia group. ASIV, astragaloside IV; HPASMCs, human pulmonary artery smooth muscle cells; $\mathrm{N}$, normoxia; H, hypoxia.

protective effects against PAH induced by MCT. Pulmonary function tests could permit accurate, reproducible assessment of the functional state of the respiratory system. It would be of interest to evaluate whether drugs exert protective effects on respiratory system. In the present study, the pulmonary functions of the animals were not examined. Thus, whether ASIV exerts protective effects on the respiratory system warrants further investigation.

The pathogenesis of MCT-induced PAH is characterized by persistent inflammation. A single MCT dose universally elevates the numbers of inflammatory cells and increases the expression of inflammatory cytokines in the lungs (14). For 



Figure 9. ASIV attenuates the increased expression of TNF- $\alpha$ and IL-1 $\beta$. (A) TNF- $\alpha$ levels in serum. (B) IL-1 $\beta$ levels in serum. (C) Relative mRNA expression levels of TNF- $\alpha$ in rat lungs. (D) Relative mRNA expression levels of IL-1 $\beta$ in rat lungs. Values are the means \pm SEM ( $n=8$ rats/group). "P<0.01 compared with the control group; ${ }^{\#} \mathrm{P}<0.05 ;{ }^{\# \#} \mathrm{P}<0.01$, compared with the MCT group. ASIV, astragaloside IV; MCT, monocrotaline; ASIV10, MCT + $10 \mathrm{mg} / \mathrm{kg} / \mathrm{day}$ ASIV group; ASIV30, MCT $+30 \mathrm{mg} / \mathrm{kg} / \mathrm{day}$ group.


Figure 10. ASIV attenuates hypoxia-induced HPAEC dysfunction. (A) TNF- $\alpha$ concentration in HPAEC culture media. (B) IL-1 $\beta$ concentration in HPAEC culture media. (C) Western blot analysis of HIF-1 $\alpha$ and VEGF protein levels in HPAECs under normoxic or hypoxic conditions. (D) HIF-1 $\alpha$ and VEGF protein levels, respectively (relative to normoxia group). Values are the means \pm SEM of 3 independent experiments. " $\mathrm{P}<0.01$ compared with the normoxia group; ${ }^{\#} \mathrm{P}<0.05 ;{ }^{\# /} \mathrm{P}<0.01$, compared with the hypoxia group. ASIV, astragaloside IV; HPAEC, human pulmonary artery endothelial cell; $\mathrm{N}$, normoxia; H, hypoxia. 
example, TNF- $\alpha$ and IL- $1 \beta$ have been found to be closely associated with the accumulation of extracellular matrix proteins in PAH lesions and poor clinical outcomes in some patients with PAH. In addition, serum levels of TNF- $\alpha$ and IL-1 $\beta$ are higher in patients with PAH than in normal controls, and serve as biomarkers of disease progression $(7,27)$. TNF- $\alpha$ elevates pulmonary arterial reactivity and inhibits the vasodilating action of prostacyclin via the downregulation of prostacyclin synthase mRNA expression (28). In addition, the overexpression of TNF- $\alpha$ in alveolar type II cells leads to an increased lung volume, alveolar enlargement and increased pulmonary artery pressure (29), while blocking TNF- $\alpha$ and IL-1 $\beta$ signaling can ameliorate pulmonary inflammation, pulmonary hemodynamics, pulmonary vascular remodeling and right ventricular hypertrophy (30-32). ASIV attenuates some inflammation-associated cardiopulmonary diseases, such as obesity-related hypertension and cigarette smoke-induced pulmonary inflammation by decreasing the levels of TNF- $\alpha$ and IL-1 $\beta(33,34)$. Consistent with these findings, in the present study, ASIV suppressed the inflammatory response in a rat model of PAH, suggesting that the anti-inflammatory action of ASIV underlies its therapeutic effects on MCT-induced PAH.

PASMCs in patients with PAH exhibit high proliferative and apoptosis-resistant properties similar to some cancer cells, which appear to be associated with the thickening and narrowing of pulmonary arteries and increased pulmonary arterial pressure, hence constituting a promising target for the treatment of PAH. In the present study, immunohistochemical analysis with an anti-PCNA antibody and TUNEL assay revealed that ASIV suppressed the proliferation and promoted the apoptosis of PASMCs in the medial wall of the pulmonary arteries. The results of the MTT assay and TUNEL assay in vitro also supported these findings. HIF-1 $\alpha$, as an oxygen-sensitive transcription factor, is involved in the crosstalk among several hypoxia-related signaling pathways and promotes pulmonary artery structural remodeling by increasing proliferation and suppressing apoptosis (35). The loss of HIF-1 $\alpha$ in PASMCs significantly suppresses the remodeling of pulmonary arteries and the associated pulmonary hypertension (36). In addition, the MAPK/ERK and PI3K/Akt signaling pathways have been recognized to mediate a wide range of functions, including proliferation, growth and survival. As regards the association between HIF-1 $\alpha$, ERK1/2 and Akt signaling, it has been reported that the overexpression of HIF-1 $\alpha$ can lead to the activation of various signaling molecules, including ERK1/2 and Akt (37). In the presents study, in the in vitro experiments, HIF-1 $\alpha$ protein expression was detected in HPASMCs. The results indicated that ASIV reversed the enhancement of HIF-1 $\alpha$ protein expression in HPASMCs induced by hypoxia. Subsequently, p-ERK1/2 and p-Akt protein expression was detected. Of note, ASIV reversed the enhancement of $\mathrm{p}$-ERK $1 / 2$ protein expression in HPASMCs induced by hypoxia, but not p-Akt protein expression (data not shown). p27 and $\mathrm{p} 21$ are cyclin-dependent kinase inhibitors that play a key role in the regulation of cell cycle progression. Recent studies have indicated that they exert inhibitory effects on PASMC proliferation $(38,39)$. It has also been reported that the suppression of proliferative signaling, such as ERK1/2 can inhibit the degradation of p27 and p21 (40). The results of the present study demonstrated that ASIV upregulated the protein expression of p27 and p21 in HPASMCs. Apoptosis is the process of normal programmed cell death and involves a large number of molecules and pathways, including $\mathrm{Bcl}-2$ family proteins and caspase signaling. The protein expression ratio of $\mathrm{Bcl}-2 / \mathrm{Bax}$ is important in the mitochondria-dependent apoptotic pathway and is associated with higher and lower apoptotic thresholds. In the present study, to determine whether ASIV-induced PASMC apoptosis is associated with the Bax/Bcl-2 and mitochondrial apoptosis pathways, the protein expression of Bcl-2, Bax, cleaved caspase-9 and cleaved caspase- 3 was detected in HPASMCs. The results revealed that ASIV upregulated the protein expression of Bax, cleaved caspase- 9 and cleaved caspase-3 in HPASMCs, but downregulated Bcl-2 protein expression. Collectively, these findings indicate that ASIV can reduce PASMC proliferation and apoptotic resistance.

In the pulmonary vasculature, PAECs are located as the innermost layer of the blood vessel and are the main barrier to the movement of molecules through the vascular wall. In $\mathrm{PAH}$, the dysfunction of PAECs leads to the impairment of endothelial-dependent vasodilatation, a decrease in anticoagulant properties, elevated levels of adhesion molecules, an enhancement of reactive oxygen species production and the release of different inflammatory cytokines (41). In addition, the dysfunction of PAECs contributes to the increased angiogenesis that underlies plexiform lesion formation (9). As markers of angiogenesis, HIF-1 $\alpha$ and VEGF are highly expressed in endothelial cells of plexiform lesions in patients with PAH (42). In the present study, it was observed that ASIV significantly reduced the increased HIF-1 $\alpha$ and VEGF protein levels in HPAECs induced by hypoxia. Furthermore, ASIV also suppressed the hypoxia-induced release of TNF- $\alpha$ and IL-1 $\beta$ in HPAECs.

In conclusion, the present study demonstrated that the administration of ASIV improved the pathological changes in pulmonary artery structural remodeling, pulmonary arterial pressure and right ventricular hypertrophy in a rat model of MCT PAH. The therapeutic effects of ASIV were associated with the improvement of the inflammatory response, PAEC dysfunction, and abnormal PASMC proliferation and apoptotic resistance. These findings provide indicate that ASIV exerts protective effects against $\mathrm{PAH}$, and may thus have potential to be developed into a promising pharmacological candidate for the treatment of PAH. However, the precise molecular mechanisms of action ASIV against PAH require further investigation. In future experiments, the authors aim to establish the Sugen 5416/hypoxia mouse model of PAH to further confirm the possible protective effects of ASIV against $\mathrm{PAH}$ and explore the precise molecular mechanisms.

\section{Acknowledgements}

Not applicable.

\section{Funding}

The present study was supported by the Science Research Foundation of Education Department of Heilongjiang Province (grant no. 2018-KYYWF-0115), China; the Heilongjiang Postdoctoral Science Foundation (grant no. LBH-Z17213), China; the Science Research Foundation of Qiqihar Medical University (grant no. QY2016M-02), China; and the National 
Research Foundation of Korea (grant no.2018R1A5A2025272), Korea.

\section{Availability of data and materials}

All data generated or analyzed during the present study are included in this published article or are available from the corresponding author on reasonable request.

\section{Authors' contributions}

HJ, JL, RZ and SCK designed the study. HJ, YJ, LG, YM, XL and $\mathrm{LS}$ conducted the experiments. $\mathrm{HJ}$ and $\mathrm{ZZ}$ performed the statistical analysis. JL, HJ, RZ and SCK wrote the manuscript. All authors read and approved the final manuscript.

\section{Ethics approval and consent to participate}

All animal experiments were approved by the Animal Care and Use Committee of the Qiqihar Medical University and conducted in accordance with the National Institutes of Health guidelines concerning the care and use of laboratory animals.

\section{Patient consent for publication}

Not applicable.

\section{Competing interests}

The authors declare that they have no competing interests.

\section{References}

1. Simonneau G, Montani D, Celermajer DS, Denton CP, Gatzoulis MA, Krowka M, Williams PG and Souza R: Haemodynamic definitions and updated clinical classification of pulmonary hypertension. Eur Respir J 53: 1801913, 2019.

2. Sahay S: Evaluation and classification of pulmonary arterial hypertension. J Thorac Dis 11 (Suppl 14): S1789-S1799, 2019.

3. Archer SL, Weir EK and Wilkins MR: Basic science of pulmonary arterial hypertension for clinicians: New concepts and experimental therapies. Circulation 121: 2045-2066, 2010.

4. Guignabert C and Dorfmuller P: Pathology and pathobiology of pulmonary hypertension. Semin Respir Crit Care Med 34 551-559, 2013.

5. Pullamsetti SS, Schermuly R, Ghofrani A, Weissmann N, Grimminger F and Seeger W: Novel and emerging therapies for pulmonary hypertension. Am J Respir Crit Care Med 189: 394-400, 2014.

6. Pugliese SC, Poth JM, Fini MA, Olschewski A, El Kasmi KC and Stenmark KR: The role of inflammation in hypoxic pulmonary hypertension: From cellular mechanisms to clinical phenotypes. Am J Physiol Lung Cell Mol Physiol 308: L229-L252, 2015.

7. Rabinovitch M, Guignabert C, Humbert M and Nicolls MR: Inflammation and immunity in the pathogenesis of pulmonary arterial hypertension. Circ Res 115: 165-175, 2014.

8. Mushaben EM, Hershey GK, Pauciulo MW, Nichols WC and Le Cras TD: Chronic allergic inflammation causes vascular remodeling and pulmonary hypertension in BMPR2 hypomorph and wild-type mice. PLoS One 7: e32468, 2012.

9. Vaillancourt M, Ruffenach G, Meloche J and Bonnet S: Adaptation and remodelling of the pulmonary circulation in pulmonary hypertension. Can J Cardiol 31: 407-415, 2015.

10. Freund-Michel V, Cardoso Dos Santos M, Guignabert C, Montani D, Phan C, Coste F, Tu L, Dubois M, Girerd B, Courtois A, et al: Role of nerve growth factor in development and persistence of experimental pulmonary hypertension. Am J Respir Crit Care Med 192: 342-355, 2015.
11. Jin H, Liu M, Zhang X, Pan J, Han J, Wang Y, Lei H, Ding Y and Yuan Y: Grape seed procyanidin extract attenuates hypoxic pulmonary hypertension by inhibiting oxidative stress and pulmonary arterial smooth muscle cells proliferation. J Nutr Biochem 36: 81-88, 2016.

12. Thenappan T, Ormiston ML, Ryan JJ and Archer SL: Pulmonary arterial hypertension: Pathogenesis and clinical management. BMJ 360: j5492, 2018.

13. Li MX, Jiang DQ, Wang Y, Chen QZ, Ma YJ, Yu SS and Wang Y: Signal mechanisms of vascular remodeling in the development of pulmonary arterial hypertension. J Cardiovasc Pharmacol 67: 182-190, 2016.

14. Nogueira-Ferreira R, Vitorino R, Ferreira R and HenriquesCoelho T: Exploring the monocrotaline animal model for the study of pulmonary arterial hypertension: A network approach. Pulm Pharmacol Ther 35: 8-16, 2015.

15. Xiong PY, Potus F, Chan W and Archer SL: Models and molecular mechanisms of world health organization group 2 to 4 pulmonary hypertension. Hypertension 71: 34-55, 2018.

16. Fu J, Wang Z, Huang L, Zheng S, Wang D, Chen S, Zhang H and Yang S: Review of the botanical characteristics, phytochemistry, and pharmacology of Astragalus membranaceus (Huangqi). Phytother Res 28: 1275-1283, 2014.

17. Li X, Qu L, Dong Y, Han L, Liu E, Fang S, Zhang Y and Wang T: A review of recent research progress on the astragalus genus. Molecules 19: 18850-18880, 2014.

18. Li L, Hou X, Xu R, Liu C and Tu M: Research review on the pharmacological effects of astragaloside IV. Fundam Clin Pharmacol 31: 17-36, 2017.

19. Qiu L, Yin G, Cheng L, Fan Y, Xiao W, Yu G, Xing M, Jia R, Sun R, Ma X, et al: Astragaloside IV ameliorates acute pancreatitis in rats by inhibiting the activation of nuclear factor- $\kappa \mathrm{B}$. Int J Mol Med 35: 625-636, 2015.

20. Liu X, Zhang J, Wang S, Qiu J and Yu C: Astragaloside IV attenuates the H2O2-induced apoptosis of neuronal cells by inhibiting $\alpha$-synuclein expression via the p38 MAPK pathway. Int J Mol Med 40: 1772-1780, 2017.

21. Wang J, Zhou Y, Wu S, Huang K, Thapa S, Tao L, Wang J, Shen Y, Wang J, Xue Y and Ji K: Astragaloside IV attenuated 3,4-benzopyrene-induced abdominal aortic aneurysm by ameliorating macrophage-mediated inflammation. Front Pharmacol 9: 496, 2018.

22. Lu Y, Li S, Wu H, Bian Z, Xu J, Gu C, Chen X and Yang D: Beneficial effects of astragaloside IV against angiotensin II-induced mitochondrial dysfunction in rat vascular smooth muscle cells. Int J Mol Med 36: 1223-1232, 2015.

23. Qian W, Cai X, Qian Q, Zhang W and Wang D: Astragaloside IV modulates TGF- $\beta 1$-dependent epithelial-mesenchymal transition in bleomycin-induced pulmonary fibrosis. J Cell Mol Med 22: 4354-4365, 2018.

24. West $\mathbf{J}$ and Hemnes A: Experimental and transgenic models of pulmonary hypertension. Compr Physiol 1: 769-782, 2011.

25. Jin H, Wang Y, Zhou L, Liu L, Zhang P, Deng W and Yuan Y: Melatonin attenuates hypoxic pulmonary hypertension by inhibiting the inflammation and the proliferation of pulmonary arterial smooth muscle cells. J Pineal Res 57: 442-450, 2014.

26. Livak KJ and Schmittgen TD: Analysis of relative gene expression data using real-time quantitative PCR and the 2(-Delta Delta C(T)) method. Methods 25: 402-408, 2001.

27. Matura LA, Ventetuolo CE, Palevsky HI, Lederer DJ, Horn EM, Mathai SC, Pinder D, Archer-Chicko C, Bagiella E, Roberts KE, et al: Interleukin-6 and tumor necrosis factor- $\alpha$ are associated with quality of life-related symptoms in pulmonary arterial hypertension. Ann Am Thorac Soc 12: 370-375, 2015.

28. Itoh A, Nishihira J, Makita H, Miyamoto K, Yamaguchi E and Nishimura M: Effects of IL-1beta, TNF-alpha, and macrophage migration inhibitory factor on prostacyclin synthesis in rat pulmonary artery smooth muscle cells. Respirology 8: 467-472, 2003.

29. Fujita M, Shannon JM, Irvin CG, Fagan KA, Cool C, Augustin A and Mason RJ: Overexpression of tumor necrosis factor-alpha produces an increase in lung volumes and pulmonary hypertension. Am J Physiol Lung Cell Mol Physiol 280: L39-L49, 2001.

30. Groth A, Vrugt B, Brock M, Speich R, Ulrich S and Huber LC: Inflammatory cytokines in pulmonary hypertension. Respir Res 15: 47, 2014.

31. Wang Q, Zuo XR, Wang YY, Xie WP, Wang H and Zhang M: Monocrotaline-induced pulmonary arterial hypertension is attenuated by TNF- $\alpha$ antagonists via the suppression of TNF- $\alpha$ expression and $\mathrm{NF}-\kappa \mathrm{B}$ pathway in rats. Vascul Pharmacol 58: 71-77, 2013. 
32. Campos M and Schiopu E: Pulmonary arterial hypertension in adult-onset still's disease: Rapid response to anakinra. Case Rep Rheumatol 2012: 537613, 2012.

33. Jiang P, Ma D, Wang X, Wang Y, Bi Y, Yang J, Wang X and Li X: Astragaloside IV prevents obesity-associated hypertension by improving pro-inflammatory reaction and leptin resistance. Mol Cells 41: 244-255, 2018.

34. Meiqian Z, Leying Z and Chang C: Astragaloside IV inhibits cigarette smoke-induced pulmonary inflammation in mice. Inflammation 41: 1671-1680, 2018.

35. Paulin R and Michelakis ED: The metabolic theory of pulmonary arterial hypertension. Circ Res 115: 148-164, 2014.

36. Ball MK, Waypa GB, Mungai PT, Nielsen JM, Czech L, Dudley VJ, Beussink L, Dettman RW, Berkelhamer SK, Steinhorn RH, et al: Regulation of hypoxia-induced pulmonary hypertension by vascular smooth muscle hypoxia-inducible factor-1 $\alpha$. Am J Respir Crit Care Med 189: 314-324, 2014.

37. Wang G, Wang JJ, Fu XL, Guang R and To ST: Advances in the targeting of HIF-1 $\alpha$ and future therapeutic strategies for glioblastoma multiforme (Review). Oncol Rep 37: 657-670, 2017

38. Fouty BW, Grimison B, Fagan KA, Le Cras TD, Harral JW, Hoedt-Miller M, Sclafani RA and Rodman DM: p27(Kip1) is important in modulating pulmonary artery smooth muscle cell proliferation. Am J Respir Cell Mol Biol 25: 652-658, 2001.
39. Mizuno S, Kadowaki M, Demura Y, Ameshima S, Miyamori I and Ishizaki T: p42/44 mitogen-activated protein kinase regulated by p53 and nitric oxide in human pulmonary arterial smooth muscle cells. Am J Respir Cell Mol Biol 31: 184-192, 2004.

40. Ashok C, Owais S, Srijyothi L, Selvam M, Ponne S and Baluchamy S: A feedback regulation of CREB activation through the CUL4A and ERK signaling. Med Oncol 36: 20, 2019.

41. Humbert M, Guignabert C, Bonnet S, Dorfmüller P, Klinger JR, Nicolls MR, Olschewski AJ, Pullamsetti SS, Schermuly RT, Stenmark KR and Rabinovitch M: Pathology and pathobiology of pulmonary hypertension: State of the art and research perspectives. Eur Respir J 53: 1801887, 2019.

42. Budhiraja R, Tuder RM and Hassoun PM: Endothelial dysfunction in pulmonary hypertension. Circulation 109: 159-165, 2004.

This work is licensed under a Creative Commons

Attribution-NonCommercial-NoDerivatives 4.0 International (CC BY-NC-ND 4.0) License. 